\title{
Role of Ethics in Information Technology During COVID-19 Pandemic: A Review
}

\author{
Sanay Jaju', Sunita Rawat ${ }^{2}$ and Abhijeet R. Raipurkar ${ }^{3}$ \\ ${ }^{1,3}$ Department of Computer Science and Engineering, Shri Ramdeobaba \\ College of Engineering and Management, Nagpur, India \\ ${ }^{2}$ Research Scholar, G. H. Raisoni College of Engineering, Nagpur, India
}

\section{ABSTRACT}

Ethical principle consists of ethics. Ethics plays an important role and have impact on individual and their lives. Whistle blowing is an important situation which has direct impact on ethics in IT. The problem raises moral queries and has social and economic implications. Organizations implement codes of ethics within their policies that highlight the moral responsibilities of users in the use of knowledge technology. Company's name can be shielded and increase worker engagement by making a work wherever moral conduct is that the norm. COVID-19 has incontestable the impotency of current technologies. The COVID-19 pandemic has raised a bunch of moral challenges; however key among these has been the chance that health care systems may have to be compelled to ration scarce essential care resources. World Health Organization (WHO) has established a global unit on Ethics and COVID-19 so as to develop recommendation on key moral queries that Member States have to be compelled to address.

\section{KEY WORDS: ETHICS, INFORMATION TECHNOLOGY, CHALLENGES POSED BY COVID-19.}

\section{INTRODUCTION}

In simple words, ethics can be said as a system of moral principles. It affects people's decision making and the way they lead their lives. It concerns with what is good and necessary for an individual and even a society and can also be described as moral philosophy. The term "Ethics" originates from the Greek word "ethos" meaning custom, character, habit or disposition.

\section{It basically covers the following dilemmas:}

- Way of living nice life

- The language of what is right and what is wrong.

\section{ARTICLE INFORMATION}

*Corresponding Author: jajuss@rknec.edu

Received 17th Oct 2020 Accepted after revision 29th Dec 2020

Print ISSN: 0974-6455 Online ISSN: 2321-4007 CODEN: BBRCBA

Thomson Reuters ISI Web of Science Clarivate Analytics USA and Crossref Indexed Journal

\section{Clarivate
Analytics}

NAAS Journal Score 2020 (4.31)

A Society of Science and Nature Publication,

Bhopal India 2020. All rights reserved.

Online Contents Available at: http//www.bbrc.in/

Doi: http://dx.doi.org/10.21786/bbrc/13.14/51
- Moral decisions, i.e., what is good and bad.

The concept of ethics has basically been derived from various religions, different philosophies, and variety of cultures. These bring in to light the topics like human rights, abortion, and even professional conduct. It is also defined as the code of morals practiced by an individual or an institution. A simple example of ethics can be taken as the- code of conduct set by a business. The field of ethics (also known as moral philosophy involves the process of systematizing, defending, and recommendation of concepts on right and wrong behaviour. In today's world, philosophers usually divide theories of ethics into three general subjects as- metaethics, normative ethics, and applied ethics.

Role of Ethics in IT: With contingent workers (people who do contingent work, i.e., a type of job in which the person neither has an implicit nor explicit contracts for long-term employment), whistle-blowing is an important topic that is taken up in any discussion of ethics in IT [Alex Dubov \& Steven Shoptaw]. Both, contingent work 
and whistle-blowing raise ethical questions and they have economic and social implications. The way in which these issues are taken up and addressed leaves a long-lasting impact not only on the individual and the employers involved, but also on the entire IT industry [2]. As previously noted, it is a way of attracting masses attention to an illegal, negligent, unethical, dangerous, and abusive act performed by an institution or any other company or organization. In some of the cases, whistleblowers are those people or employees of an organization who send, sell, and reveal information about their organization in order to gain revenge for a perceived wrong. In most of the cases they act in an ethical way to correct what according to them is wrongdoing of the company, at times on a great personal risk.

Importance of Ethics in IT: Ethics in IT (Information Technology) is important as it creates a culture of responsibility, integrity, trust, and excellence in the sense of use of resources [Wang, C. J., C. Y. Ng, and R. H. Brook]. It promotes a sense of privacy, confidentiality of information and an unauthorized access to the computer networks, which helps prevent conflict and dishonesty. Many organizations put in affect codes of ethics into their policies which highlight the ethical responsibilities of the users in the way they use information technology. The codes of ethics help ensure resources of IT are used in an authorized way and only for authorized works. They also help prevent the share of privilege access, like passwords, among the users. This ensures prevention of malicious attacks in computer systems. It also promotes respectful use of IT by preventing users to deny others the access to computer networks. It helps prevent unauthorized copying, deletion or modification of personal information, such as files and emails. Ethical code of conduct prevents users from adding software which are malicious, i.e., infected by virus, into the computer systems. Also it makes users resist from misusing or vandalizing resources of IT.

Role of Ethics in Reducing Problem in Information Technology: In order to increase the trust of the stake holders of your organization and gain popularity among masses, you can create a workplace such that the norm followed is the organization's ethical conduct. Ethical risk can be reduced by implementing following key points: -

- Assessing your resources and needs honestly.

- Try to establish a powerful foundation.

- Create a culture of integrity from top to bottom in your workplace.

- Keep a "values focus" in moments big and small.

- Re-evaluate and revise if required.

Assessing your resources and needs honestly: Whenever you start a program, beginning with an accurate picture of the available strengths and the vulnerable areas makes a difference. Assessing your risks in the beginning is a good starting point in your internal efforts, which should be followed by gap analysis which should be continued by assessment of program. An essential piece can be audit reports. Information (resources) can be gathered in various ways. Opinions and experiences of masses can help provide deep rich, deep "snapshot" of the ethics in your institution. Surveys can be conducted by third party, which could provide an opportunity for gathering data from masses (or within the institute from the employees). This can give comparative results and the data can be analyzed by relevant people.

Try to establish powerful foundation: Once you have the list of your needs, resources can be put together to establish a robust ethics and compliance program. This program can be used as a powerful tool to reduce pressure so that the standards which were being compromised and misconduct which was being observed were reduced. Also retaliation amongst whistle-blowers would decrease. When a company commits resources towards ethics, a difference is seen- major of the employees feel depressurized so they don't break rules and lesser misdeeds take place.

Create culture of integrity from top to bottom in your workplace: People have a basic feeling of getting along with the company. They try to fit in and conform to the norms. It is not pleasant to admit, but most of the people's standards of ethics are malleable. Many might retain a desire to "do the right thing", but how right is defined gets influenced significantly by the organization they keep. Also culture matters a lot.

Keep "Value focus" in moments big and small: Ethics is about choices-big and small. Institutions having integrity have their "values focus" at the front in both monotonous and extra ordinary moments. Corporate values of an institution should come into action and should be reflected in the tasks of everyday life of the institution like:

- Human resource policies and its implementation.

- Rewarding mechanism.

- Hiring and retention.

- Management of performance of the employees and their evaluation.

- And finally taking decisions on promotion.

Re-evaluate and revise if required: Situations, parameters, and even needs will change. You should always know what's working out for you and what's not, what new susceptibility have emerged, what advancements you have made and where incomplete work is. Be regular and disciplined about revisiting the state of ethics and compliance in the institution. Assessments of risks, follow-up surveys, and on-going focus groups allow your program to be relevant and its risk is minimized.

Challenges posed by COVID-19 pandemic for IT: COVID-19 showed the non-usefulness of presently available technologies. Major of the cities around the world have applications of digital informational and smart technology. Some of the cities especially Global South cities don't have this kind of applications [Abusaada, H., Elshater]. These applications provide 
the help for detection of pandemic and the infected individuals, also they help in stopping hazards that can be potentially be caused by the virus. Also regarding the Information Technology and Communications, the cities in Global South can't compare with Western and European countries [Abusaada, H., Elshater]. During the COVID-19 pandemic, the cities which were dependent on technology, have failed in coping with the losses the COVID-19 pandemic brought with it [Wang, C. J., C. Y. Ng, and R. H. Brook]. This was seen due to the less effectiveness of the cities when it comes to smart digital technology.

Hence, contextualization of broader constraints over planning and management in the urban should be considered like:

- Improvement in the disclosure and transparency of information or data.

- Making people think in a different way, stopping people from getting information and rather make them accustomed to collect and make information and also create new ideas.

- A smart city uses smart technology-based applications and it also observes the competences of its citizens against the technology. A smart city can be said as a city of communications, traffic, network, knowledge. Also they analyse the collected big-data through suitable, strong, wireless network (network of sensors) for every condition, which are ubiquitous, sheltered, and accessible to each and every citizen at no extra cost. Smart technology includes:

- The physical structures like buildings, electronics and electrical components, software and ITCs infrastructure, renewable source of energy.

- Connectivity of network like fibre optics to home, $\mathrm{Wi}-\mathrm{Fi}$ in the complete city, NFC (Near Field Communications), Cyber-physical systems (CPS) and Bluetooth, IoT (Internet of Things).

- Biometric sensors should be used in healthcare and E-governance.

- Robust urban environments should be made to antagonize the environmental emergence, or political or economic conditions.

Role of Ethics in solving current pandemic challenges: The current pandemic situation caused by COVID-19 gave rise to many challenges related to ethics; key challenges being the possibility that there would be scarce critical care resources for the health care systems [Elgesem, D]. Policies for rationing during this pandemic vary from healthcare systems to organization to constitutions (jurisprudence). Some of the states presently have uniform or unvarying policies for healthcare whereas some don't have a single policy. Where there are policies, the primary considerations for a patient are that $\mathrm{s} / \mathrm{he}$ should get benefits of treatment. In some places there is a disagreement on factors that are appropriate for considerations in the ethical sense. This is where real ethical challenges arise [Elgesem, D]. The challenge for the healthcare systems is that how can they handle the inflow of so many patients during the COVID-19 pandemic. Since COVID-19 has spread to majority countries of the world, bioethicists and physicians have been working with healthcare professionals in order to create new or revise existing policies in order to create a suitable criterion of decisions for allocations.

Working Group on Ethics and COVID-19: The World Health Organization (WHO) formed an international "Working Group on Ethics and COVID-19" for developing advice on the main ethical problems that are needed to be addressed by the Member States. This expert group was formed in February, 2020 in order to advise the WHO's technical units about the COVID-related work and the ethical aspects regarding to that work. From the formation of this expert group, the activities in which it has been engaged are

- To give advice on the ethical aspects on the research related to COVID-19.

- To provide a practical guidance on the ethical values' application focusing research based on COVID-19 as per the journal published," Public Health Ethics".

- A brief on the policies regarding the allocations and setting priority for the care related to COVID-19.

- In-order to facilitate the reviewing of protocols during the pandemic due to COVID-19 rapidly, emergency standard operating procedures is to be developed for the committees of human research.

Community of global ethics responded to COVID-19 by coming together and working on the implications of ethics during the pandemic of COVID-19 [Lenca M, Vayena E]. Also for strengthening of communications between groups, collaborations of different ethical groups and the collaboration of different groups, is done by Global Health Ethics team of the World Health Organization.

Role of Cyber laws for challenges in IT from country to country: The challenges faced by the information technology field vary from country to country depending on how their cyber laws are designed. A new cyber security initiative was introduced in China which said that it would not collect any data in an illegal sense. Now this law was passed in China in the year, 2020 whereas in many other countries they existed like from the start of their digital era. This tells us that anyone whose data was on Chinese servers; it was easily accessible to the Chinese government. This was possible only due to a difference in the cyber laws of that particular country.

The possible challenges which can be found in IT are: -

- Digital Data Threat - Since transactions are increasingly being done online, cybercriminals get a bigger enticement. There are various establishments who look forward to mine data, for instance, the information of a customer in order to create a treasured IP (Intellectual Property).

- Hacking - It is the act of probing into another system in an illegal or unauthorized manner in order to steal some confidential information or even destroy the same. This has grown drastically in the 
past few years. Internet, in today's world, has made information for performing a hack available at our fingertips making it easier for the people, who don't have a bit of knowledge, to perform a hack.

- Supply Chain Interconnection - Increasingly, supply chains are getting interconnected. Various companies (or organizations or institutions) are influencing customers and vendors to connect with them into their networks, which in turn is making the firewall (or security wall) of that company weak.

\section{CONCLUSION}

We saw that ethics is apprehensive for what is best for an individual or a group of individuals (or society). It is also known as moral philosophy. It helps prevent the wrongdoings of people like whistle-blowers. It is an important part of an organization so that a culture of trust, integrity and responsibility can be observed. It dispirits the user from misusing any resource of ITC (Information Technology and Communication). We can reduce the ethical risks by assessing needs honestly, establishing a robust foundation, inculcating beliefs of integrity, keeping "values focus", and revising if needed. Smart technologies help to resolve challenges posed by COVID-19 pandemic. Due to global spread of COVID-19, physicians, bioethicists and other healthcare professional have come together to see to it that we get back to our normal life by reducing the extent of it. WHO's expert team," Working Group on Ethics and COVID-19" is putting in all its efforts too. We also explored the different types of challenges like hacking, phishing, data mining, that IT faces. In all we can say that the role of Ethics in Information Technology in this challenging period of the pandemic of COVID-19 is finding a great importance.

\section{REFERENCES}

Abusaada, H., Elshater, A. COVID-19 Challenge, Information Technologies, and Smart Cities: Considerations for Well-Being. Int. Journal of Com. WB 3, 417-424 (2020).
Alex Dubov \& Steven Shoptaw, "The Value and Ethics of Using Technology to Contain the COVID-19 Epidemic“, The American Journal of Bioethics, 2020, DOI: $10.1080 / 15265161.2020 .1764136$.

Amy L. McGuire, Mark P. Aulisio, F. Daniel Davis, Cheryl Erwin, Thomas D. Harter, Reshma Jagsi, Robert Klitzman, Robert Macauley, Eric Racine, Susan M. Wolf, Matthew Wynia, Paul Root Wolpe \& The COVID-19 Task Force of the Association of Bioethics Program Directors (ABPD) (2020) Ethical Challenges Arising in the COVID19 Pandemic: An Overview from the Association of Bioethics Program Directors (ABPD) Task Force, The American Journal of Bioethics, 20:7, 15-27,

Elgesem, D. (2008). Information Technology Research Ethics. In J. Van den Hoven \& J. Weckert (Eds.), Information Technology and Moral Philosophy (Cambridge Studies in Philosophy and Public Policy, pp. 354-375). Cambridge: Cambridge University Press Kolfschooten HV, "EU Coordination of Serious CrossBorder Threats to Health: The Implications for Protection of Informed Consent in National Pandemic Policies", European Journal of Risk Regulation 2019; 10: 63551.

Lenca M, Vayena E, “On the responsible use of digital data to tackle the COVID-19 pandemic", Nature Medicine 2020; 26: 463-4. DOI:10.1038/s41591-020-0832-5.

Martin R, Conseil A, Longstaff A, "Pandemic influenza control in Europe and the constraints resulting from incoherent public health laws", BMC Public Health 2010; 10.

Risk-Based security's 2019 Year end data breach quickview, p. 4-17.

Wang, C. J., C. Y. Ng, and R. H. Brook, "Response to COVID-19 in Taiwan: Big data analytics, new technology, and proactive testing”, 2020, JAMA 323(14): 1341-1342.

Yan SJ, Chughtai AA, Macintyre CR, "Utility and potential of rapid epidemic intelligence from internetbased sources", International Journal of Infectious Diseases 2017; 63: 77-87. 